EXPERIMENTAL STUDY

\title{
Developmental expression and spermatogenic stage specificity of transcription factors GATA-1 and GATA-4 and their cofactors FOG-1 and FOG-2 in the mouse testis
}

\author{
Ilkka Ketola $^{1}$, Mikko Anttonen ${ }^{1}$, Tommi Vaskivuo ${ }^{3}$, Juha S Tapanainen ${ }^{3}$, Jorma Toppari ${ }^{2}$ and \\ Markku Heikinheimo ${ }^{1,4}$ \\ ${ }^{1}$ Children's Hospital and Program for Developmental and Reproductive Biology, Biomedicum Helsinki, University of Helsinki, O0290 Helsinki, Finland, \\ ${ }^{2}$ Departments of Physiology and Pediatrics, University of Turku, 20520 Turku, Finland, ${ }^{3}$ Department of Obstetrics and Gynecology, University of Oulu, \\ 90220 Oulu, Finland and ${ }^{4}$ Department of Pediatrics, University of Tampere, 33520 Tampere, Finland and Washington University in St Louis, St Louis,
} Missouri 63110, USA

(Correspondence should be addressed to M Heikinheimo, Biomedicum Helsinki, PO Box 63, Room B525b, O0014 University of Helsinki, Helsinki, Finland; Email: markku.heikinheimo@helsinki.fi)

(M Heikinheimo is now at Cellular Signalling Laboratory, Department of Anatomical Sciences, University of Bologna, Via Irnerio 48, I-40126 Bologna, Italy)

\begin{abstract}
Objective: The transcription factors GATA-1 and GATA-4 have been implicated in the regulation of testicular development and function. Their cofactors FOG-1 and FOG-2 are expressed in the gonads, but their cell-specific and developmental expression in the testis remains unresolved. Therefore, we analyzed GATA-1, GATA-4, FOG-1 and FOG-2 expression in detail, from undifferentiated male urogenital ridge to adult testis.

Methods: Immunohistochemistry and in situ hybridization were applied on mouse testicular samples. Results: GATA-4 and FOG-2, but not GATA-1 or FOG-1, were expressed as early as in the male urogenital ridge. FOG-2 expression was localized in the Sertoli cells at embryonal day 12.5 (E12.5), but it diminished with advancing fetal testicular development. In E17.5 testis, FOG-2 was present only in the testicular capsule and a subset of fetal Leydig cells. FOG-1 was expressed from E15.5 Sertoli cells onwards, whereas GATA-1 was not detected during the fetal period at all. In the postnatal testis, FOG-2 was abundantly expressed immediately after birth, but in adult testis its expression was predominantly restricted to stage VII-XII seminiferous tubules. Stage specificity was also found for FOG-1, which, similarly to GATA-1, was abundantly expressed in stage VII-XII tubules during adulthood.

Conclusions: Our results indicate that FOG-2, in addition to GATA-4, has a role in early gonadal development and sexual differentiation, and FOG-1 at later fetal stages, while GATA-1 executes its action postnatally. The findings suggest that, in contrast to the hematopoietic system and the heart, GATA-1 and GATA- 4 do not use FOG-1 and FOG-2 respectively as their only cofactors during the early stages of testicular development.
\end{abstract}

European Journal of Endocrinology 147 397-406

\section{Introduction}

Members of the GATA transcription factor family are conserved through evolution in different species. Growing evidence suggests that they have important roles in the differentiation and development of several tissues, from phylogenetically low species to mammals. GATA proteins can be divided into two subgroups based on their structural homology and tissue distribution, although these subgroups also show overlapping expression in some organs. The members of the hematopoietic subgroup, GATA-1, GATA-2 and GATA-3 have well-established roles in the regulation of erythropoiesis, megakaryopoiesis and $\mathrm{T}$ cell differentiation (13). Members of the other subfamily, including GATA-4, GATA-5 and GATA-6, are expressed in the heart, gut epithelium, yolk sac endoderm, gonads and in a number of other tissues (4-8).

GATA-1, the founding member of GATA factors, is expressed in mouse testicular Sertoli cells from postnatal day 7 onwards (9). Later in development it is expressed only in adult Sertoli cells of stage VII-IX seminiferous tubules. GATA- 1 has been shown to transactivate inhibin- $\alpha$ and inhibin/activin $\beta$-B-subunit 
genes in vitro $(10,11)$, indicating an important role for it in regulating testicular function. It is also a potential repressor of Müllerian inhibiting substance (MIS) expression during the fetal period as well as in puberty in the mouse (12).

Of GATA factors, the role of GATA-4 in sexual differentiation and gonadal development has been studied most intensively. GATA-4 is expressed in somatic cell lineages both in the testis and the ovary, and it has been suggested to be an important regulator of gonadal gene expression (13-16). Accordingly, it is a potent transactivator of several testicular genes, including those for MIS $(14,17,18)$, inhibin- $\alpha$ (15), steroidogenic acute regulatory protein (19), aromatase (20, 21) and steroidogenic factor-1 (SF-1) (21).

The multitype zinc finger proteins FOG-1 (22) and FOG-2 $(23,24)$ have been shown to modulate the transcriptional activity of GATA factors. They either activate or inhibit the functions of GATA proteins in a tissue- and cell-specific manner (22, 24-28). FOG-1 and FOG-2 also act through GATA-independent mechanisms and can replace each other's functions, at least in certain situations $(23,29)$. Based on the results of gene disruption studies, FOG-1 seems to be essential for normal erythropoiesis and megakaryopoiesis, whereas FOG-2 is needed for proper heart morphogenesis and coronary vessel development (29-31).

Northern blot analysis has revealed that FOG-1 and FOG-2 are expressed in the adult testis (22-24). In addition, neonatal rat primary Sertoli cells express FOG-2, as studied by RT-PCR (32). Based on the results of studies on the hematopoietic system and heart morphogenesis, GATA and FOG proteins can also be anticipated to co-operate in other organs such as the gonads. This is also suggested by the results of a recent study indicating a role for FOG-2 in the control of MIS expression in postnatal Sertoli cells (32).

Thus far, only very little is known about the cellspecific expression and regulation of FOG-1 and FOG-2 in the testis. Neither have the expression patterns of GATA-1 and GATA-4 been evaluated in the earliest stages of gonadal development. Knowledge of their precise cellular and developmental expression is, however, important for understanding of the biological significance of gonadal GATA and FOG proteins, whose interaction in vitro has been demonstrated. We therefore explored in detail the temporal and spatial testicular expression patterns of GATA-1 and GATA-4, as well as those of their cofactors FOG-1 and FOG-2, from the early embryonic period to adulthood in mice.

\section{Materials and methods}

\section{Animals}

Mouse embryos, fetal and postnatal testes were obtained by mating CBA or NMRI mice. For estimating embryonal age, noon of the day on which the copulating plug was found was considered as embryonal day (E) 0.5. Precise staging of dissected embryos was performed using The Atlas of Mouse Development (33). PCR analysis (34) of the SRY gene in genomic DNA was conducted in order to determine the sex of 10and 12-day embryos. Animal studies were conducted in accordance with the NIH Guide for the Care and Use of Laboratory Animals.

\section{Immunohistochemistry}

Testicular samples were fixed in $4 \%$ paraformaldehyde and embedded in paraffin. Tissue sections $(6-8 \mu \mathrm{m})$ were subjected to immunohistochemistry using commercial rat monoclonal antimouse GATA-1 IgG (no. sc-265; Santa Cruz Biotechnology, Santa Cruz, CA, USA), goat polyclonal antimouse GATA-4 IgG (no. sc1237; Santa Cruz Biotechnology), goat polyclonal antimouse FOG-1 (no. sc-9361; Santa Cruz Biotechnology), rabbit polyclonal antimouse FOG-2 (no. sc-10755; Santa Cruz Biotechnology) or non-immune IgG or secondary antibodies as the primary antibody. Antibodies were used at 1:200-1:500 dilution. An avidin-biotin immunoperoxidase system was used to visualize bound antibody (Vectastain Elite ABC Kit; Vector Laboratories, Burlingame, CA, USA), 3,3'-diaminobenzidine (Sigma Chemicals, St Louis, MO, USA) was used as the chromogen and the development reaction occurred in the presence of $0.03 \% \mathrm{H}_{2} \mathrm{O}_{2}$. Samples were analyzed by light and phase contrast microscopy (Leica DMRXA microscope; Leica AG, Heerbrugg, Switzerland).

\section{In situ hybridization}

Mouse embryos or dissected tissue were washed briefly in phosphate-buffered saline (PBS) and then fixed in 4\% paraformaldehyde in PBS and subjected to in situ hybridization as previously described (35). Tissue sections $(8-10 \mu \mathrm{m})$ were incubated with $1 \times 10^{6}$ c.p.m. of $\left[{ }^{33} \mathrm{P}\right]$-labeled antisense or sense riboprobe (1000$3000 \mathrm{Ci} / \mathrm{mmol}$; Amersham Life Technologies, Arlington Heights, IL, USA) in a total volume of $80 \mu \mathrm{l}$. The riboprobe for FOG-2 was prepared from an $800 \mathrm{bp}$ BamH1-Kpn1 fragment subcloned from the pCS2 + -FOG-2 full-length expression vector (23). The expression pattern for FOG-2 was studied on adjacent tissue sections whenever possible in immunohistochemistry and in situ hybridization. The results were further confirmed by performing control in situ hybridization experiments with appropriate sense riboprobes. In situ hybridization and immunohistochemical studies were repeated at least three times using embryos/testes from at least three animals. 


\section{Results}

\section{FOG-1, but not GATA-1, is expressed in late fetal testis}

Neither GATA-1 nor FOG-1 proteins were present in the E10.5 male urogenital ridge or in E12.5 or E13.5 testis
(Fig. 1, data shown for E10.5). After complete gonadal differentiation, FOG-1 protein was evident in the testicular cords in E15.5 and E17.5 testis (Fig. 1 and data not shown). It was present only in the nuclei of Sertoli cells, while gonocytes remained FOG-1 negative. Neither Leydig cell precursors nor other interstitial cells expressed FOG-1 (Table 1).

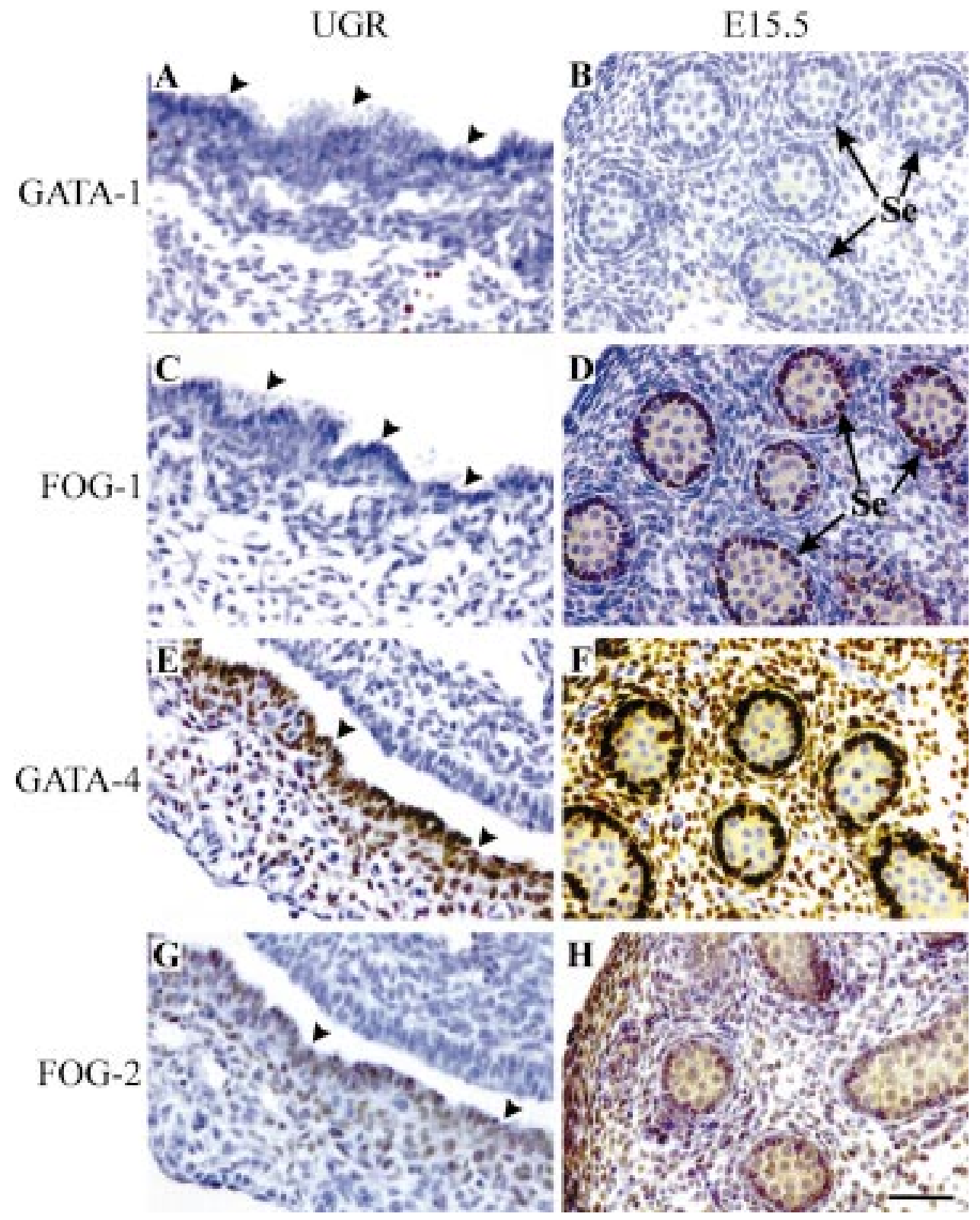

Figure 1 Immunohistochemistry of GATA-1, FOG-1, GATA-4 and FOG-2 in E10.5 male mouse urogenital ridge (UGR) and E15.5 testis. GATA-1 (A) and FOG-1 (C) were not expressed in the urogenital ridge, whereas GATA-4 (E) and FOG-2 (G) were abundantly expressed at that stage of gonadal development. In E15.5 testis, FOG-1 (D) and GATA-4 (F) were co-expressed in the Sertoli cells. In E15.5 testis, FOG-2 $(\mathrm{H})$ was expressed in the testicular capsule and in a subset of interstitial cells. Some of the Sertoli cells were still weakly positive for FOG-2. Original magnification $\times 200$; bar $=50 \mu \mathrm{m}$. Arrowheads, urogenital ridge; Se, Sertoli cell. 
Table 1 Expression of GATA-1, GATA-4, FOG-1 and FOG-2 during testicular development.

\begin{tabular}{lcccc}
\hline & GATA-1 & GATA-4 & FOG-1 & FOG-2 \\
\hline Genital ridge & - & + & - & + \\
Late fetal (E17.5) & & & & \\
$\quad$ Sertoli & - & + & + & - \\
Leydig & - & + & - & + \\
Gonocyte & - & - & - & - \\
Newborn & & & & \\
$\quad$ Sertoli & - & + & + & + \\
Leydig & - & + & - & + \\
Gonocyte & - & - & - & + and - \\
Adult & & & & - \\
$\quad$ Sertoli & $+{ }^{*}$ & + & $+^{*}$ & - \\
Leydig & - & + & - & $+^{*}$ \\
Germ cells & - & - & - & \\
\hline
\end{tabular}

${ }^{*}$ Predominantly in stages VII, VIII, IX, X XI and XII.

\section{GATA-4 and FOG-2 are expressed as early as in the urogenital ridge}

GATA-4 and FOG-2 mRNAs and proteins were detected in the urogenital ridge of E10.5 male embryos (Fig. 1). However, a small proportion of the urogenital ridge cells were GATA-4 and/or FOG-2 negative. GATA-4 expression was obvious through fetal testicular development (E12.5, E13.5, E15.5 and E17.5) and was localized in the Sertoli and Leydig cells and tunica albuginea (Fig. 1, data shown for E15.5). The results on GATA-4 protein expression are compatible with our earlier findings concerning GATA-4 mRNA (15). Diverging from the findings on GATA-4, FOG-2
mRNA and protein expression diminished with advancing fetal testicular development. In E13.5 testis (data not shown), FOG-2 protein was present in the Sertoli cells, but the staining intensity was lower than that in E10.5 urogenital ridge cells. In late fetal testis (E17.5, data not shown), cells of the testicular cords, i.e. Sertoli cells and gonocytes, were essentially devoid of FOG-2 mRNA and protein. Some of the interstitial cells and cells in the tunica albuginea expressed FOG-2 mRNA and protein at this developmental stage.

\section{FOG-1 and GATA-1 co-localize in adult Sertoli cells in a stage-specific manner}

Immunohistochemical analysis demonstrated that FOG-1 protein was detectable only in the Sertoli cells throughout postnatal testicular development (Figs. 2 and 3). However, in adult mouse testis some of the seminiferous tubules remained FOG-1 negative or the staining intensity was very weak. Detailed analysis of the sections revealed that FOG-1 protein was most intensively expressed in the Sertoli cells of late stage VII-XII seminiferous tubules (Fig. 3). From postnatal day (P) 7 onwards FOG-1 expression in the testis was similar to that previously described for GATA-1 (Fig. 2). A striking difference was detected in the staining intensities of GATA-1 and FOG-1 between Sertoli cells of stage VII-XII tubules compared with Sertoli cells in the other stages. However, Sertoli cells of stage II-VI seminiferous tubules expressed GATA-1 and FOG-1 protein, though the intensity was much lower than in Sertoli cells of stage VII-XII seminiferous tubules (Fig. 3).

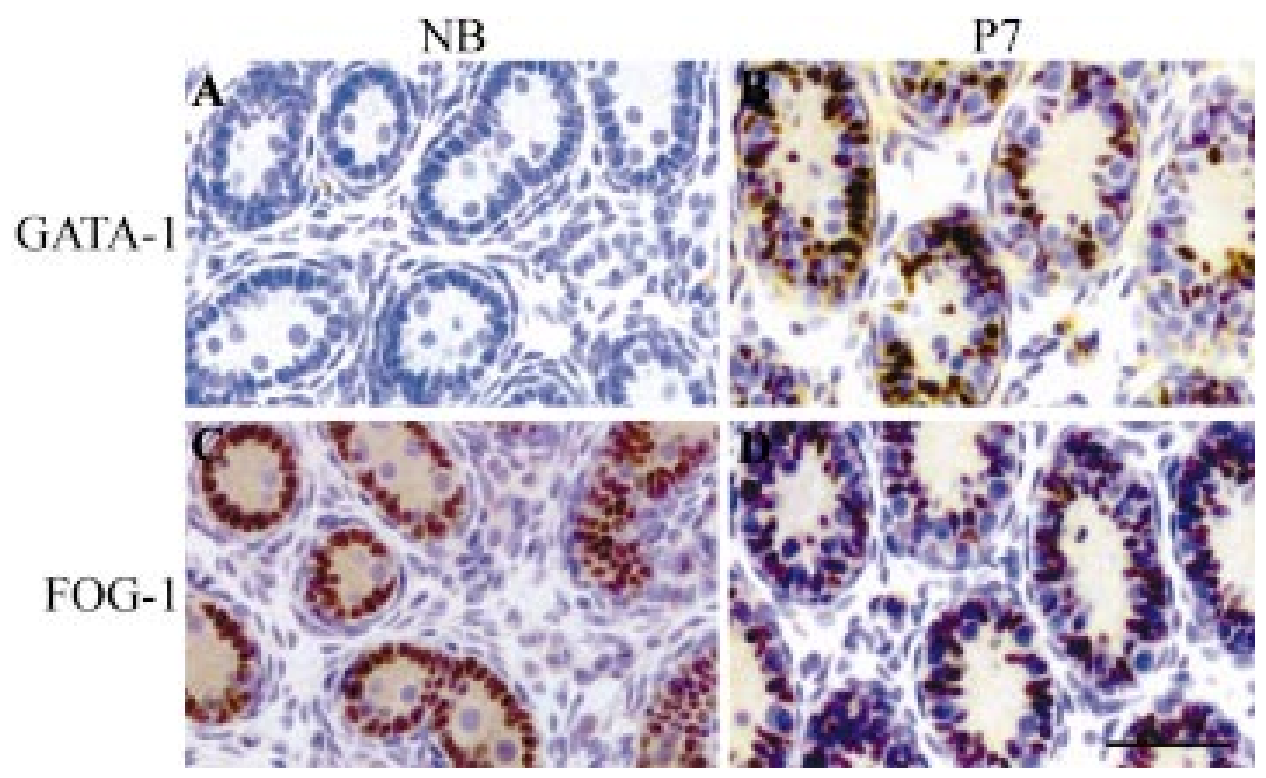

Figure 2 Immunohistochemistry of GATA-1 and FOG-1 in the newborn (NB) and day-7 (P7) mouse testis. FOG-1 (C), but not GATA-1 (A), was expressed in the Sertoli cells of newborn mouse (dark brown nuclei). At day 7 (D), FOG-1 was co-expressed with GATA-1 (B) in Sertoli cells. Interstitial Leydig cells were negative for GATA-1 and FOG-1. Original magnification $\times 200$; bar $=50 \mu \mathrm{m}$. 


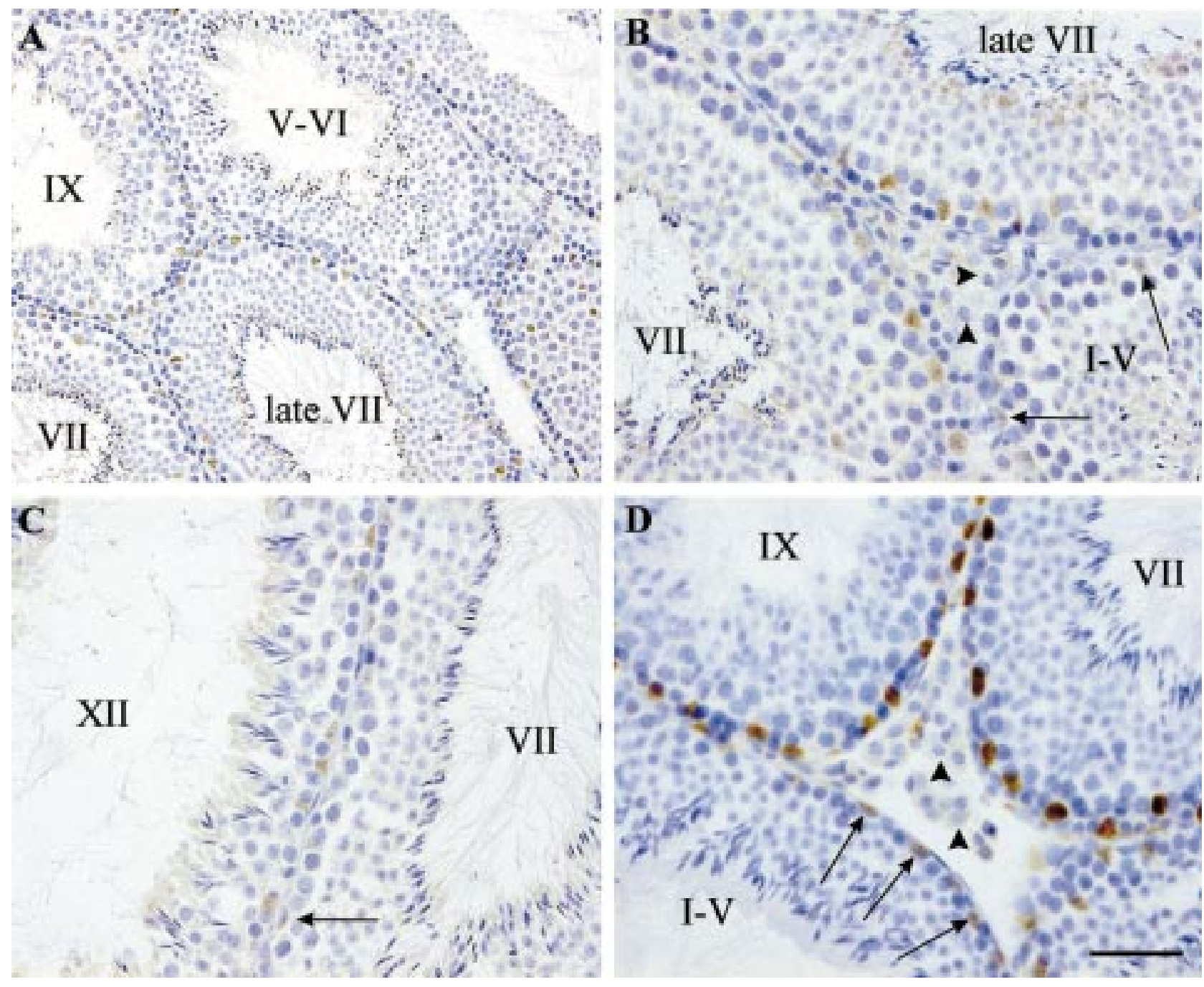

Figure 3 Immunohistochemistry of FOG-1 (A-C) and GATA-1 (D) in day-60 (P60) mouse testis. In the adult testis, FOG-1 and GATA-1 were expressed predominantly in late stage VII-XII seminiferous tubules. Note the subtle expression of both FOG-1 (B) and GATA-1 (D) in the Sertoli cells (arrows), also in stage I-V tubules. Leydig cells (arrowheads) were negative for FOG-1 (B) and GATA-1 (D). Roman numbers mark the spermatogenic stages of seminiferous tubules. Original magnification $\times 100$ in $(A)$ and $\times 200$ in $(B-D)$; bar $=50 \mu \mathrm{m}$.

\section{FOG-2 is expressed in the postnatal testis in a stage-specific manner}

As judged by in situ hybridization, FOG-2 mRNA was abundantly expressed in the newborn mouse testis, and the results remained positive throughout postnatal testicular development (P7, P14, P25, P60) (Fig. 4). The first signs of stage-specific FOG-2 mRNA expression were seen along with advancing spermatogenesis in P25 testis, when clear variability in signal intensity was seen between different tubules (data not shown). In adult testis, stage VII-XII tubules were positive for FOG-2 mRNA and in the other stages the signal was very weak (Fig. 4).
Using in situ hybridization, it is not possible to determine the specific cell types expressing FOG-2 in newborn, P7 and P14 testis due to limitations in the resolution of this method. However, testicular growth and development enhance the resolution and allow us to conclude that, in day-25 testis, FOG-2 transcripts are localized mainly in the germ cells (data not shown). We could not exclude the possibility that some of the Sertoli cells were also positive at this age. In contrast, interstitial cells were FOG-2 negative at P25. In P60 testis, the spermatogenic stage specificity of FOG-2 expression in the germ cells of seminiferous tubules was clearly evident. FOG-2 mRNA transcripts were present in late stage VII seminiferous tubules 


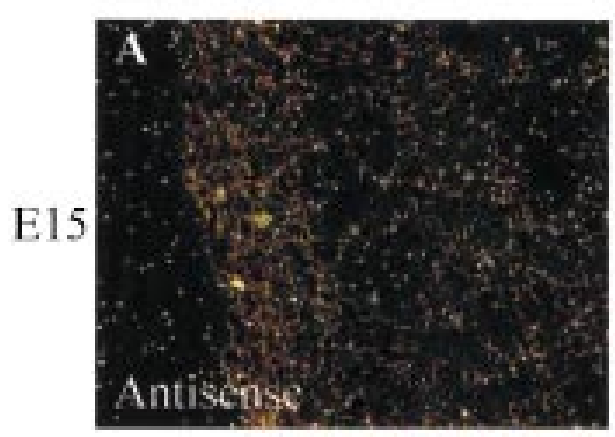

\section{FOG-2}
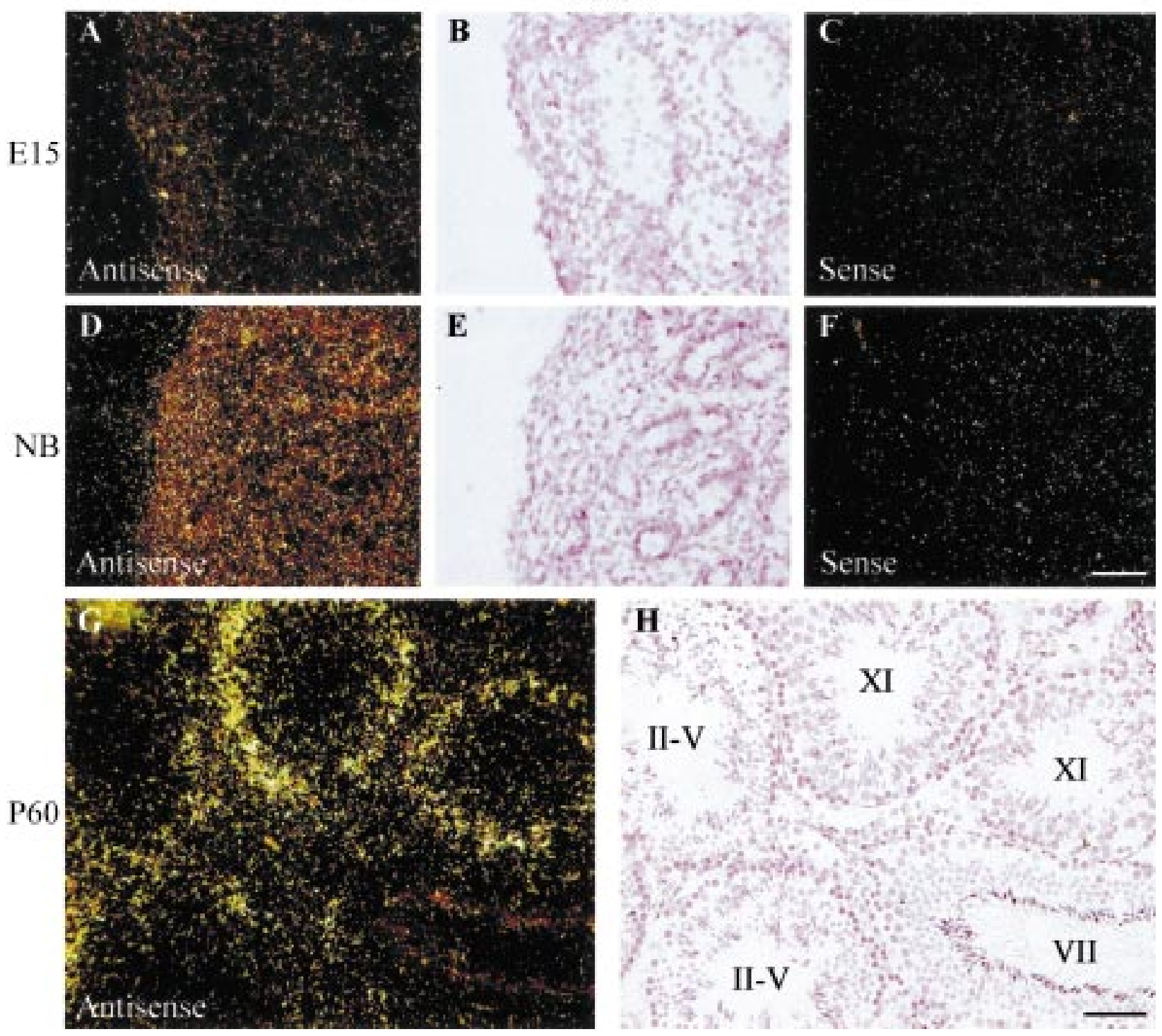

Figure 4 In situ hybridization of FOG-2 mRNA in E15.5 (A-C), newborn (NB) (D-F) and day-60 (P60) (G and H) mouse testis. Darkfield antisense views are shown in (A), (D) and (G), and respective hematoxylin-eosin brightfields in (B), (E) and (H). Sense control darkfield views for E15.5 (A) and newborn (D) are shown in (C) and (F) respectively. In the newborn testis (D), FOG-2 mRNA was abundantly expressed as compared with fetal E15.5 testis (A). In the P60 testis (G), FOG-2 transcripts were expressed in a stagespecific manner. Roman numbers in $(\mathrm{H})$ mark the spermatogenic stages of seminiferous tubules. Original magnification $\times 200$ in $(A-F)$ and $\times 100$ in $(\mathrm{G}$ and $\mathrm{H})$; bar $=50 \mu \mathrm{m}$.

in mid-pachytene spermatocytes. The signal was most intense from early mid-pachytene to late diplotene spermatocytes in stage VIII-XII tubules and it was present until step 9 spermatids. The Sertoli and Leydig cells remained negative for FOG-2 mRNA in the adult testis.

FOG-2 protein was localized in the Sertoli cells in the testes of newborn, and 7- and 14-day-old mice (Fig. 5). Cells of the tunica albuginea, and interstitial cells, presumably Leydig cells, were also FOG-2 positive at this stage. In the newborn mouse testis, some of the gonocytes showed FOG-2 immunoreactivity, but it disappeared during the first week of testicular development. Surprisingly, from P25 onwards FOG-2 protein was no longer detected in Sertoli cells, and the number of FOG-2-positive Leydig cells also decreased remarkably. In the seminiferous tubules, only the nuclei of round spermatids were FOG-2 positive. In 
NB

P7

P14
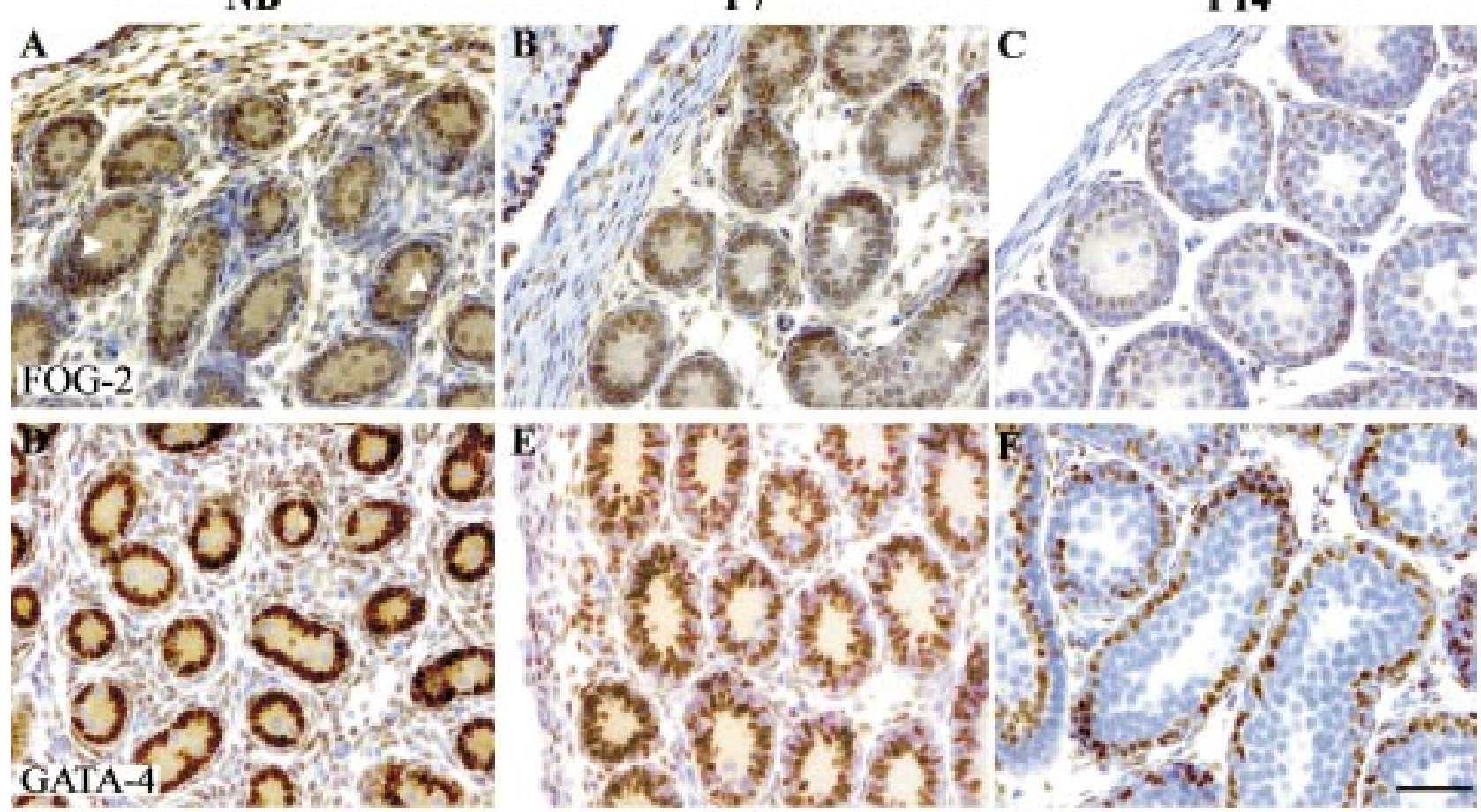

P60
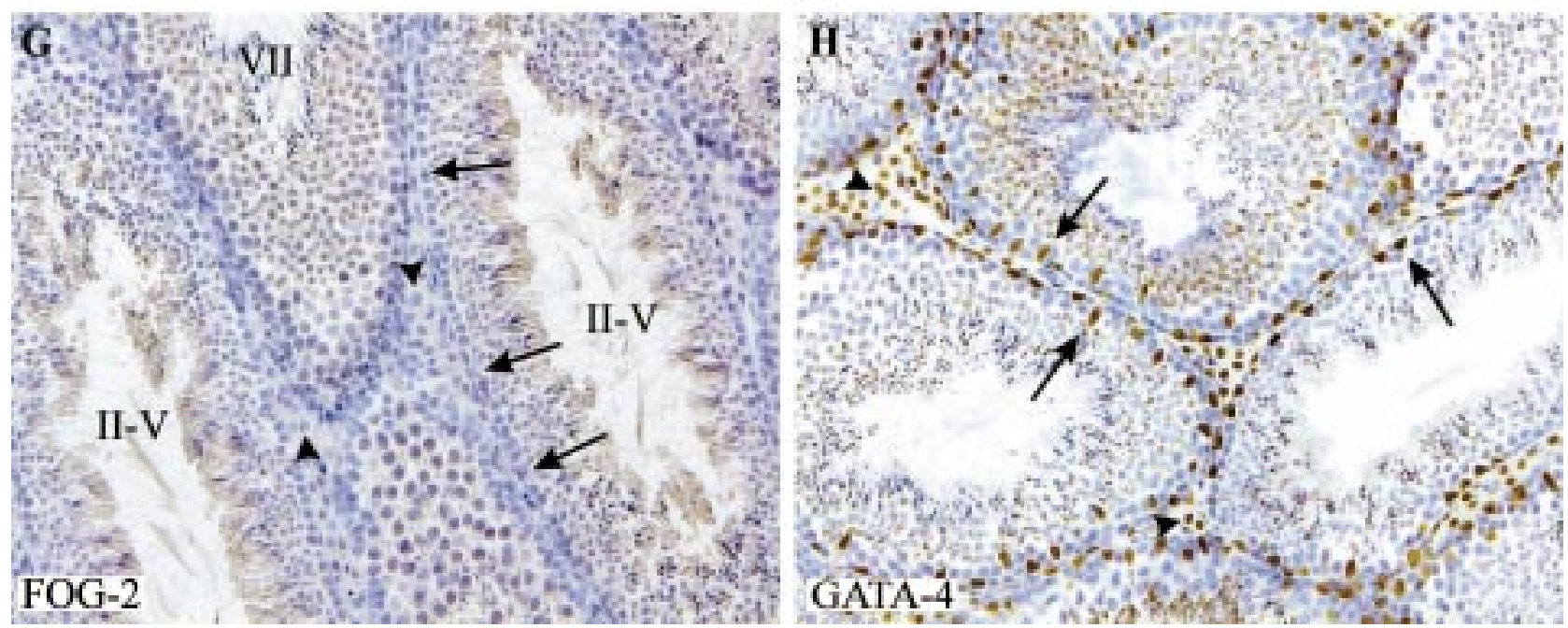

Figure 5 Immunohistochemistry of FOG-2 (A-C and G) and GATA-4 (D-F and H) in the newborn (NB), day-7 (P7), day-14 (P14) and day-60 (P60) mouse testis. In the newborn mouse testis, FOG-2 (A) was expressed in Sertoli and Leydig cells and in the cells of the testicular capsule. At that time, some of the gonocytes were also positive for FOG-2 (white arrowheads). In P7 (B) and P14 (C) testis, spermatogonia (white arrowheads) did not express FOG-2. In P60 testis (G), FOG-2 was no longer expressed in Sertoli (arrows) and Leydig cells (black arrowheads). GATA-4 was expressed in Sertoli and Leydig cells throughout postnatal development (D-F and H). Acrosomes stained non-specifically for GATA-4 $(\mathrm{H})$. Roman numbers in $(\mathrm{G})$ mark the spermatogenic stages of seminiferous tubules. Original magnification $\times 200$ in $(A-F)$ and $\times 100$ in $(G$ and $H)$; bar $=50 \mu \mathrm{m}$.

the adult testis, Sertoli and Leydig cells as well as the cells of the testicular capsule were totally devoid of FOG-2 protein. In addition to nuclear staining, cytoplasmic FOG-2 immunoreactivity was present up to step 9 spermatids.

\section{GATA-4 is expressed in somatic testicular cells from fetal to adult age}

GATA-4 protein was present in the somatic cells, i.e. Sertoli and Leydig cells, throughout testicular 
development (Figs. 1 and 5), but it was not detected in any type of germ cell at any fetal or postnatal age studied. In the adult mouse testis, GATA-4 protein was evenly expressed in the Sertoli cells at different stages of the seminiferous tubules.

\section{Discussion}

GATA-1 and GATA-4 have been suggested to be important in the regulation of gonadal development and function. Recent studies have shown that FOG-1 and FOG-2 modulate the transcriptional activity of GATA proteins in a tissue- and cell-specific manner in vitro and in vivo. However, virtually nothing is known of the interactions of GATA and FOG proteins in the testis. Furthermore, cell-specific FOG-1 and FOG-2 expression in the testis has not been described. In this work, we investigated the developmental expression patterns of FOG-1 and FOG-2 in the mouse testis, as well as the expression of GATA-1 and GATA-4 during the earliest stages of testicular development.

Importantly, GATA-4 and FOG-2 were co-expressed as early as in the E10.5 urogenital ridge of male embryos, before testicular cords have formed. This further underlines the importance of GATA-4 in early testicular development, and also indicates a role for FOG-2 in the earliest steps of gonadal development. The expression of these factors overlaps with that of several key regulators of gonadal development and sexual differentiation. GATA-4 and FOG-2 are expressed just before SRY, SOX-9, MIS and DAX-1, which thus execute their actions after GATA-4 and FOG-2 have appeared in the developing gonad. Furthermore, Wilms' tumor 1 and SF-1 are expressed simultaneously with GATA-4 and FOG-2 as early as in the E10.5 urogenital ridge. Of interest, GATA-4 interacts with SF-1 to regulate MIS expression (17), and FOG-2 has been proposed to have a role in this process during the postnatal period (32).

In the present and previous studies, GATA-1 has not been found before postnatal ages (9). However, in the present work we show that FOG-1 protein is expressed in E15.5 testis, co-localizing with GATA-4 in the Sertoli cells. Therefore, it is plausible to presume that FOG-1 interacts with GATA-4 during fetal testicular development and modifies the effects of GATA-4 on its target genes. We have previously reported that GATA-4 activates the inhibin- $\alpha$ promoter in Leydig and granulosa cell lines (15). Of interest, inhibin- $\alpha$ is first seen in fetal testis at E16 (36), thus coinciding with the appearance of FOG-1 expression. However, further studies, including transactivation experiments, are needed to evaluate whether or not FOG-1 acts as GATA-4's cofactor in the regulation of inhibin- $\alpha$ gene expression in the fetal testis.

FOG-1 has a well-established role as a cofactor for GATA-1 in the hematopoietic system $(26,29,37)$.
FOG-1 is also a potent cofactor for GATA-1 in the postnatal testis. In early postnatal Sertoli cells, FOG-1 expression coincides with that of GATA-1 from the appearance of the first wave of spermatogenesis. Later on, the number of FOG-1- and GATA-1-positive Sertoli cells declines, and in adult seminiferous tubules these factors are predominantly expressed in stage VII-XII tubules. Thus, FOG-1 could well act as a GATA-1 cofactor during postnatal testicular development. This proposal is supported by the results of a previous study demonstrating that GATA-1 transactivates the inhibin/ activin $\beta$-B-subunit gene (11). FOG-1 might well act as a GATA-1 repressor in its action on the inhibin/ activin $\beta$-B-subunit, since the expression of this gene is lowest in Sertoli cells at stages VII-XII of the seminiferous epithelial cycle (38). It is of interest to note that not only GATA-1 but also GATA-4 have been shown to transactivate the inhibin/activin $\beta$-B-subunit gene in Sertoli and Leydig cell lines (11). Co-transfection with GATA-1 and GATA-4 transactivated the inhibin/activin $\beta$-B-subunit promoter more than either of them alone. Based on the FOG-1 expression described in this study and the results of previous cotransfection studies on the same promoter (11), we propose that FOG-1 may interact with either GATA-1 or GATA-4 in regulating this gene in the testis.

Two earlier studies have indicated that GATA-4 protein is expressed not only in Sertoli and Leydig cells but also in germ cells in the postnatal mouse as well as fetal and prepubertal human testis $(14,15)$. In the present study, we did not, however, detect GATA-4 protein in any types of germ cell at any stage of testicular development. The present results are in line with our previous findings on GATA-4 mRNA and protein expression in adult mouse, rat and human testis $(15,16)$. The reason for these contradictory results on GATA-4 Sertoli and germ cell expression remains unclear. The use of different mouse strains and a slightly different immunohistochemical method, including fixation and antigen retrieval, might in part explain these differences. The cell identification has been based on morphological features only in these studies, and distinction between Sertoli cells and germ cells is not always clear. Whether there are also species-specific differences in the testicular GATA-4 expression remains to be confirmed. Nevertheless, abundant GATA-4 expression in Sertoli and Leydig cells further suggests that this transcription factor also has an important role in the somatic cells of the postnatal testis.

In the newborn mouse testis, FOG-2 is expressed in the Sertoli and Leydig cells, as well as in the testicular capsule. There is a profound change in FOG-2 expression along with advancing spermatogenesis. Namely, somatic cells cease to express FOG-2 in the adult testis. In contrast, FOG-2 is expressed in midpachytene spermatocytes to step 9 spermatids, especially in stage VIII-XII seminiferous tubules. At this point transcriptional activity ceases almost completely. 
Therefore, it is logical to assume that the transcriptional machinery is downregulated. FOG-2 expression in Sertoli cells is highest during the proliferative phase of these cells, and it ceases during the third postnatal week, when terminal differentiation of Sertoli cells occurs. Proliferating Sertoli cells abundantly express GATA-4 according to earlier studies $(15,16)$. Of interest, some of the gonocytes of newborn mice expressed FOG-2 protein, but at day 7 all spermatogonia were devoid of FOG-2. Furthermore, FOG-2 is expressed in maturing, but not in fully differentiated adult Leydig cells.

Due to the descriptive nature of this study, it is not possible to make conclusions as to the definitive interactions among various developmental factors. However, on the basis of the data presented here and in earlier transactivation studies, we propose that GATA-1, GATA-4, FOG-1 and FOG-2 have important roles in regulating gonadal development and function. Their expression patterns partially overlap, suggesting both common and differential roles in the murine testis. The findings also suggest that, in contrast to the hematopoietic system and heart, GATA-1 and GATA-4 do not use FOG-1 and FOG-2, respectively, as their only cofactors during the early stages of testicular development.

\section{Acknowledgements}

This work was supported by the University Central Hospital in Helsinki and Helsinki University Research Funds and Foundation (to I K, M A and M H), The Finnish Pediatric Research Foundation (to I K), The Finnish Medical Foundation (to I K and M A), The Sigrid Jusélius Foundation (to J S T and M H), Oulu University Central Hospital (to $\mathrm{J} \mathrm{S} \mathrm{T}$ and $\mathrm{T} \mathrm{V}$ ), The Academy of Finland (to J S T, J T and M H), The Finnish Research Programme on Environmental Health, of the Academy of Finland, and Turku University Central Hospital (to J T).

\section{References}

1 Pevny L, Simon MC, Robertson E, Klein WH, Tsai SF, D’Agati V et al. Erythroid differentiation in chimaeric mice blocked by a targeted mutation in the gene for transcription factor GATA-1. Nature $1991349257-260$.

2 Tsai FY, Keller G, Kuo FC, Weiss M, Chen J, Rosenblatt M et al. An early haematopoietic defect in mice lacking the transcription factor GATA-2. Nature $1994371221-226$.

3 Pandolfi PP, Roth ME, Karis A, Leonard MW, Dzierzak E, Grosveld FG et al. Targeted disruption of the GATA3 gene causes severe abnormalities in the nervous system and in fetal liver haematopoiesis. Nature Genetics $19951140-44$.

4 Arceci RJ, King AA, Simon MC, Orkin SH \& Wilson DB. Mouse GATA-4: a retinoic acid-inducible GATA-binding transcription factor expressed in endodermally derived tissues and heart. Molecular and Cellular Biology 199313 2235-2246.
5 Soudais C, Bielinska M, Heikinheimo M, MacArthur CA, Narita N, Saffitz JE et al. Targeted mutagenesis of the transcription factor GATA-4 gene in mouse embryonic stem cells disrupts visceral endoderm differentiation in vitro. Development $1995 \mathbf{1 2 1}$ 3877-3888.

6 Morrisey EE, Ip HS, Tang Z, Lu MM \& Parmacek MS. GATA-5: a transcriptional activator expressed in a novel temporally and spatially-restricted pattern during embryonic development. Developmental Biology 1997183 21-36.

7 Morrisey EE, Ip HS, Lu MM \& Parmacek MS. GATA-6: a zinc finger transcription factor that is expressed in multiple cell lineages derived from lateral mesoderm. Developmental Biology 1996177 309-322.

8 Narita N, Heikinheimo M, Bielinska M, White RA \& Wilson DB. The gene for transcription factor GATA- 6 resides on mouse chromosome 18 and is expressed in myocardium and vascular smooth muscle. Genomics 199636 345-348.

9 Yomogida K, Ohtani H, Harigae H, Ito E, Nishimune Y, Engel JD et al. Developmental stage- and spermatogenic cycle-specific expression of transcription factor GATA-1 in mouse Sertoli cells. Development $1994 \mathbf{1 2 0} 1759-1766$.

10 Feng ZM, Wu AZ \& Chen CL. Testicular GATA-1 factor up-regulates the promoter activity of rat inhibin alpha-subunit gene in MA-10 Leydig tumor cells. Molecular Endocrinology 199812 378-390.

11 Feng ZM, Wu AZ, Zhang Z \& Chen CL. GATA-1 and GATA-4 transactivate inhibin/activin beta-B-subunit gene transcription in testicular cells. Molecular Endocrinology 200014 1820-1835.

12 Beau C, Rauch M, Joulin V, Jegou B \& Guerrier D. GATA-1 is a potential repressor of anti-Mullerian hormone expression during the establishment of puberty in the mouse. Molecular Reproduction and Development $2000 \mathbf{5 6} 124-138$.

13 Heikinheimo M, Ermolaeva M, Bielinska M, Rahman NA, Narita $\mathrm{N}$, Huhtaniemi IT et al. Expression and hormonal regulation of transcription factors GATA-4 and GATA-6 in the mouse ovary. Endocrinology 1997138 3505-3514.

14 Viger RS, Mertineit C, Trasler JM \& Nemer M. Transcription factor GATA-4 is expressed in a sexually dimorphic pattern during mouse gonadal development and is a potent activator of the Mullerian inhibiting substance promoter. Development 1998 125 2665-2675.

15 Ketola I, Rahman N, Toppari J, Bielinska M, Porter-Tinge SB, Tapanainen JS et al. Expression and regulation of transcription factors GATA-4 and GATA-6 in developing mouse testis. Endocrinology $19991401470-1480$.

16 Ketola I, Pentikainen V, Vaskivuo T, Ilvesmaki V, Herva R, Dunkel L et al. Expression of transcription factor GATA-4 during human testicular development and disease. Journal of Clinical Endocrinology and Metabolism 200085 3925-3931.

17 Tremblay JJ \& Viger RS. Transcription factor GATA-4 enhances Mullerian inhibiting substance gene transcription through a direct interaction with the nuclear receptor SF-1. Molecular Endocrinology 199913 1388-1401.

18 Watanabe K, Clarke TR, Lane AH, Wang X \& Donahoe PK. Endogenous expression of Mullerian inhibiting substance in early postnatal rat Sertoli cells requires multiple steroidogenic factor-1 and GATA-4-binding sites. PNAS 200097 1624-1629.

19 Silverman E, Eimerl S \& Orly J. CCAAT enhancer-binding protein beta and GATA-4 binding regions within the promoter of the steroidogenic acute regulatory protein (StAR) gene are required for transcription in rat ovarian cells. Journal of Biological Chemistry $199927417987-17996$.

20 Jin T, Zhang X, Li H \& Goss PE. Characterization of a novel silencer element in the human aromatase gene PII promoter. Breast Cancer Research and Treatment $2000 \mathbf{6 2} 151-159$.

21 Tremblay JJ \& Viger RS. GATA factors differentially activate multiple gonadal promoters through conserved GATA regulatory elements. Endocrinology $2001 \mathbf{1 4 2} 977-986$.

22 Tsang AP, Visvader JE, Turner CA, Fujiwara Y, Yu C, Weiss MJ et al. FOG, a multitype zinc finger protein, acts as a cofactor for 
transcription factor GATA-1 in erythroid and megakaryocytic differentiation. Cell 199790 109-119.

23 Tevosian SG, Deconinck AE, Cantor AB, Rieff HI, Fujiwara Y Corfas G et al. FOG-2: a novel GATA-family cofactor related to multitype zinc-finger proteins friend of GATA-1 and U-shaped. PNAS 199996 950-955.

24 Svensson EC, Tufts RL, Polk CE \& Leiden JM. Molecular cloning of FOG-2: a modulator of transcription factor GATA-4 in cardiomyocytes. PNAS $199996956-961$.

25 Lu JR, McKinsey TA, Xu H, Wang DZ, Richardson JA \& Olson EN. FOG-2, a heart- and brain-enriched cofactor for GATA transcription factors. Molecular and Cellular Biology 199919 4495-4502.

26 Fox AH, Liew C, Holmes M, Kowalski K, Mackay J \& Crossley M. Transcriptional cofactors of the FOG family interact with GATA proteins by means of multiple zinc fingers. EMBO Journal 1999 $182812-2822$

27 Holmes M, Turner J, Fox A, Chisholm O, Crossley M \& Chong B. hFOG-2, a novel zinc finger protein, binds the co-repressor mCtBP2 and modulates GATA-mediated activation. Journal of Biological Chemistry 1999274 23491-23498.

28 Svensson EC, Huggins GS, Dardik FB, Polk CE \& Leiden JM. A functionally conserved N-terminal domain of the friend of GATA-2 (FOG-2) protein represses GATA4-dependent transcription. Journal of Biological Chemistry 2000275 20762-20769.

29 Tsang AP, Fujiwara Y, Hom DB \& Orkin SH. Failure of megakaryopoiesis and arrested erythropoiesis in mice lacking the GATA-1 transcriptional cofactor FOG. Genes and Development $1998121176-1188$.

30 Tevosian SG, Deconinck AE, Tanaka M, Schinke M, Litovsky SH, Izumo $\mathrm{S}$ et al. FOG-2, a cofactor for GATA transcription factors, is essential for heart morphogenesis and development of coronary vessels from epicardium. Cell 2000101 729-739.
31 Svensson EC, Huggins GS, Lin H, Clendenin C, Jiang F, Tufts R et al. A syndrome of tricuspid atresia in mice with a targeted mutation of the gene encoding Fog-2. Nature Genetics 200025 353-356.

32 Tremblay JJ, Robert NM \& Viger RS. Modulation of endogenous GATA-4 activity reveals its dual contribution to Mullerian inhibiting substance gene transcription in Sertoli cells. Molecular Endocrinology $2001151636-1650$.

33 Kaufman MH. The Atlas of Mouse Development. London: Academic Press, 1992.

34 Cormand B, Avela K, Pihko H, Santavuori P, Talim B, Topaloglu H et al. Assignment of the muscle-eye-brain disease gene to $1 \mathrm{p} 32-$ p34 by linkage analysis and homozygosity mapping. American Journal of Human Genetics 199964 126-135.

35 Wilkinson D. In Situ Hybridization: A Practical Approach. Oxford: IRL Press, 1992.

36 Tone S, Katoh Y, Fujimoto H, Togashi S, Yanazawa M, Kato Y et al. Expression of inhibin alpha-subunit gene during mouse gametogenesis. Differentiation $1990 \mathbf{4 4} 62-68$

37 Crispino JD, Lodish MB, MacKay JP \& Orkin SH. Use of altered specificity mutants to probe a specific protein-protein interaction in differentiation: the GATA-1:FOG complex. Molecular Cell 1999 $3219-228$

38 Kaipia A, Penttila TL, Shimasaki S, Ling N, Parvinen M \& Toppari J. Expression of inhibin beta A and beta B, follistatin and activin-A receptor messenger ribonucleic acids in the rat seminiferous epithelium. Endocrinology 1992131 2703-2710.

Received 5 March 2002

Accepted 22 May 2002 